\title{
Robotics in Colorectal Surgery
}

\author{
J. Hance T. Rockall A. Darzi \\ Department of Surgical Oncology and Technology, Imperial College London, London, UK
}

\section{Key Words}

Robotics · Telemanipulators · Colorectal surgery · Laparoscopic surgery $\cdot$ Da Vinci ${ }^{\mathrm{TM}}$ surgical system

\begin{abstract}
Minimally invasive surgery has been shown to offer many advantages to general surgical patients but has not been widely adopted for colorectal disease. Initial fears surrounding the oncological safety of laparoscopic colectomies have largely subsided but the technical challenges still remain. Surgical robots or telemanipulators present the laparoscopic surgeon with unrivaled dexterity and vision, which may allow colonic resections to be completed with greater ease. Although initial studies suggest promising results using currently available systems, it will take further time for patient benefits to be proven, therefore justifying the greater expense of operating with this new technology.
\end{abstract}

Copyright $(2004$ S. Karger AG, Base

\section{Minimally Invasive Colorectal Surgery}

The introduction of the minimally invasive approach is one of the most important advances in modern surgery. Global benefits to patients include decreased post-operative pain, shorter hospital stays and earlier resumption to normal activities [1,2]. This approach has been applied to colorectal surgery and the same advantages have been demonstrated [3-5]. It then remains to be asked why this technique, which offers so many potential benefits to patients, has not become the standard practice in colorectal surgery?

\section{KARGER}

Fax +41613061234 E-Mail karger@karger.ch www.karger.com
(C) 2004 S. Karger AG, Basel 0253-4886/04/0215-0339\$21.00/0

Accessible online at: www.karger.com/dsu
With the rapid acceptance of laparoscopic cholecystectomy, many surgeons predicted that minimally invasive techniques would be applied to other abdominal procedures, including colectomy. Indeed, the first reported laparoscopic colectomy was performed over 10 years ago [6], but recent data from the USA suggests that only $3 \%$ of colectomies have been performed laparoscopically [7].

Laparoscopic colorectal surgery is technically more demanding than open colonic surgery and highlights the difficulties common to all laparoscopic surgery. The laparoscopic surgeon must view the operative field on a distant video monitor, leading to a change in the normal hand-eye-target axis [8]. In addition, this image is twodimensional with the resultant loss of stereoscopic depth perception, requiring the surgeon to learn new compensatory strategies. These changes in operative view are compounded by the camera being held by an assistant and not under the direct control of the primary surgeon. With the extended operative times of laparoscopic colorectal surgery, fatigue may cause the assistant to present the surgeon with a wandering image [9].

Standard laparoscopic surgery requires the use of long rigid instrumentation, which leads to a substantial reduction in dexterity. Additionally, the surgeon's movements are reversed by the 'fulcrum effect' of the abdominal wall. The most important effect on dexterity is the loss of 'degrees of freedom', with standard laparoscopic instruments limited to four while there are considered to be seven 'degrees of freedom' available to the surgeon during open surgery [10]. This makes tasks such as ligation and suturing, which are routine in open colectomy, relatively complex in laparoscopic surgery and almost impossible unless performed in the most optimal part of the operative field [11]. All of these factors lead to laparoscopic

Mr. J. Hance, Clinical Research Fellow

Department of Surgical Oncology and Technology, Imperial College London

10th Floor, QEQM Building, St. Mary's Hospital

Praed Street, London W2 1NY (UK)

Fax +44 207886 1810, E-Mail j.hance@imperial.ac.uk 
colorectal surgery having a substantial learning curve [12, 13], which has meant that despite many surgeons have attempted this technique, few have incorporated it as a part of their regular practice.

A further obstacle to the adoption of this technique are concerns over the oncological safety of laparoscopic colorectal surgery, as most of the resections are for malignant disease [14]. Although the final results of the large randomized trials comparing laparoscopic colectomy with the traditional open approach remain outstanding [15-17], interim studies suggest equivalent survival and recurrence rates for the minimally invasive technique $[18,19]$. The initial reports of port-site metastases are now thought to be due to inexperience [20].

Some of the inherent technical difficulties with standard laparoscopic surgery may be alleviated by the use of robots designed for minimally invasive surgery. Although referred to as 'robots', these machines do not perform pre-program tasks autonomously, as the name might suggest, but are under the direct control of the surgeon.

\section{Robotic Camera Holders in Colorectal Surgery}

The first robots used in laparoscopic surgery assisted the primary surgeon by holding the endoscopic camera, providing a stable platform, which does not become fatigued and is under the control of the surgeon. Two systems are commercially available at present: Automated Endoscopic System for Optimal Positioning (AESOP ${ }^{\mathrm{TM}}$, Computer Motion, Calif., USA) [21], which utilizes voice control, and Endoassist ${ }^{\mathrm{TM}}$ (Armstrong Healthcare Ltd, Bucks., UK) [22], which relies on a head-motion sensor to track the surgeon's progress. Although two robotic camera holders are commercially available there is only information available demonstrating the clinical use of $\mathrm{AESOP}^{\mathrm{TM}}$ in colorectal resections.

AESOP $^{\mathrm{TM}}$ consists of a single robotic positioning arm, a control box and a headset microphone. The system responds to verbal commands of the surgeon to keep the relevant surgical field in view. Ballantyne's group [23] in the USA presented a retrospective review of case notes comparing laparoscopic colectomies with and without the use of AESOP ${ }^{\mathrm{TM}}$. Eleven patients underwent colectomy in the non-robotic group compared with 15 patients in the robotic-assisted group. Results showed no significant difference in surgical outcome between cases performed with $\mathrm{AESOP}{ }^{\mathrm{TM}}$ or a human assistant as measured by operative time, length of postoperative stay and number of complications. The authors did not comment on how many of the procedures required the help of an assistant in addition to $\mathrm{AESOP}^{\mathrm{TM}}$ but stated that the average number of port sites required for robotic and human assistance was 3.1 and 3.6 respectively.

A more recent study published from Germany attempted to quantify whether using a robotic camera holder allowed the surgeon to operate without any assistance [24]. This study looked at 41 consecutive bowel resections for both benign and malignant disease including two anterior resections. For this latter procedure it was necessary to reposition the laparoscope to an alternative port though this was achieved without having to reposition the robot. During all procedures the bowel was exteriorised to complete the anastomosis, which required the help of an assistant. The authors demonstrated that the laparoscopic component of all the procedures could be completed without assistance and the open component of each procedure, which required assistance, accounted for a range of between 30\% (right hemicolectomy) and 15\% (anterior resection) of total operative time. In addition, this study reported no intra-operative complications and similar rate of post-operative complications to traditional laparoscopic colorectal surgery.

The authors of both studies were unable to objectively quantify any advantages from using the robot, though subjectively they commented upon the benefits of having direct control over the operative field with a concomitant reduction in wandering of the camera. Although it is possible to infer from Ballantyne's study that assistance was not required in the majority of robotic cases from the number of port sites required, the fact remains that if the surgeon ran into difficulty they required an a assistant. In the second study, all cases required an assistant. Though there are advantages to using a robotic camera holder, current evidence fails to unequivocally support this. The value of 'single surgeon' surgery is questionable with the majority of these procedures being carried out in teaching hospitals, where there is not normally a problem gaining assistance. However, these robot camera systems have led to the development of the more complex surgical robots, which may offer significant advantages.

\section{Telemanipulators in Colorectal Surgery}

The next generation of surgical robots, telemanipulators, not only provide a stable camera platform but also provide the surgeon with manipulator arms and interchangeable surgical instruments. These systems are set up in a master-slave configuration with the surgeon sitting at 
a console, with their hands placed on 'master' handles. Their movements are then translated via computer software to the 'slave' robot's arm at the site of the operation. It follows that surgeon is in direct control of the operation. This arrangement offers advantages to the minimally invasive surgeon. Dexterity is enhanced via EndoWrists ${ }^{\mathrm{TM}}$ technology, returning seven degrees of freedom to the surgeon, via intuitive control of microwristed instrument located within the abdominal cavity. The computer interface between the master and slave units allow motionscaling facilitating precise movements and tremor elimination. The design of the master console restores the natural hand-eye-target axis, which may reduce surgical fatigue during long procedures. Finally, the surgeon is provided with a magnified three-dimensional image of the operative field, which is under direct control. Although primarily designed to facilitate endoscopic cardiac surgery, the same benefits offered by telemanipulators can be applied to general surgery. Cadiere et al. [25] performed the first telerobotic general surgical cases in 1997. Two systems have been used in clinical practice in abdominal surgery namely da Vinci ${ }^{\mathrm{TM}}$ surgical system (Intuitive Surgical, Mountain View, Calif., USA) and Zeus ${ }^{\mathrm{TM}}$ (Computer Motion). Currently there is a lack of data supporting the use of Zeus in colorectal surgery. This may be in part due to fairly recent approval by the Federal Drug Administration board for its use in abdominal surgery, unlike the da Vinci ${ }^{\mathrm{TM}}$ surgical system, which has been in use since 1997.

Pioneers across the world have applied the da Vinci ${ }^{\mathrm{TM}}$ system to colorectal surgery, to establish whether minimally invasive bowel resections can be achieved with greater technical ease. There are a small number of series demonstrating the feasibility of bowel resections ranging from right-sided ileo-caecal resections to abdomino-perineal excisions of rectum [26-31].

Weber et al. [31] were the first to publish their experiences with telerobotic-assisted resections, performing one sigmoid colectomy and one right hemicolectomy both for benign disease. The robot was used to mobilise the bowel, while division of the mesentery and anastomosis were completed by traditional laparoscopic techniques. The average operative time was 50\% longer than traditional laparoscopic resections but the authors felt that this was greatly due to their inexperience with this new technology. Subjectively, the surgeons felt the robot addressed many of the shortcomings of traditional laparoscopic colectomy making dissection easier. However, they did note a number of limitations whist using the systems. Firstly, whilst performing the right-sided operation it was neces- sary to disengage the robot in order to reposition the patient from Trendelenburg's to reverse Trendelenburg's position. This is relatively time consuming and if required many times during a procedure, would add considerably to the overall operative time. Mobilisation of the splenic flexure during the sigmoid colectomy also had to be completed with traditional laparoscopic instruments, as the robotic instruments are shorter. The greatest limitation with the da Vinci ${ }^{\mathrm{TM}}$ system, however, was the lack of tactile feedback, which in less experienced hands could lead to inadvertent damage to delicate tissues such as the bowel wall.

A more recent study compared 6 telerobotic colorectal cases with matched laparoscopic equivalent cases to establish whether a benefit of this new technique could be demonstrated [27]. The cases included 2 right hemicolectomies, 3 sigmoid colectomies and 1 rectopexy. The surgeons utilised the robot in a similar manner to Weber et al. [31], performing only the colorectal dissection before completing the procedure with more conventional laparoscopic techniques. End points measured were operative time, patient blood loss, hospital stay and cost. They reported a significantly longer 'incision to extubation time' for the robotic-assisted cases (165 $\mathrm{min}$ ) as compared to laparoscopic cases (108 min). There were no significant differences in blood loss, hospital stay or cost, although the latter did not include the capital expenditure on the robot. The authors commented that the present generation of robots requires repositioning to facilitate accessing multiple sites within the abdomen for colorectal surgery and the resultant increase in operative time cancels any benefits of using this technology for colorectal surgery.

Both of above studies have largely concentrated on using the telerobot to perform the dissection for colonic procedures, which requires access to a large proportion of the abdominal cavity. Rectal dissection involves operating in much more limited field. This operative field is more analogous to operating in the thoracic cavity, the role for which da Vinci ${ }^{\mathrm{TM}}$ was originally designed. The surgeon's ability to perform a nerve-sparing mesorectal excision of the rectum could be enhanced by the unprecedented views into the pelvis provided by the 3-D image and improved dexterity from EndoWrists ${ }^{\mathrm{TM}}$ instrumentation [32].

The largest series to date of robotic rectal surgery only consists of 8 cases, made up of 6 anterior resections and 2 abdomino-perineal resections of rectum [28]. The mean operative times were longer than would be expected for conventional laparoscopic resections. However, the surgeon chose to complete the entire colonic dissection with 
the assistance of the robot, which entailed repositioning of the robot during the procedure. Our centre has suggested performing only the rectal dissection with da Vin$\mathrm{ci}^{\mathrm{TM}}$, completing the left colonic dissection by conventional laparoscopic methods. This avoids manoeuvring of the slave platform whist the patient is asleep [32]. Suture rectopexy is one operation, which can be performed entirely with the da Vinci ${ }^{\mathrm{TM}}$ system remaining in one anatomical location. In our series of 6 robotic-assisted rectopexies, we reported similar results to conventional laparoscopy. Subjectively it was felt the procedure was easier to master using the da Vinci ${ }^{\mathrm{TM}}$ as compared to completing the dissection with traditional laparoscopic instruments [33].

Vibert et al. [30] have used da Vinci ${ }^{\mathrm{TM}}$ to suture an intra-abdominal colorectal anastomosis. The robot allowed a continuous, multilayered anastomosis to be performed in confined operative field of the pelvis. Although interesting, it is unlikely that suture anastomosis will have a significant role to play now that stapled anastomosis are well established in colorectal surgery.

\section{Training and Future Developments}

Although telemanipulators were designed to overcome many of the obstacles of video laparoscopy, the operator still has to acquire new skills different from their existing repertoire. At present, surgeons utilising telemanipulators for colorectal surgery are accomplished laparoscopic surgeons and previous laparoscopic surgical experience has been shown to shorten the learning curve of robotic surgery [34]. However, one of potential benefits of telemanipulators is to facilitate less experienced surgeons to perform minimally invasive surgery. Therefore, it is necessary for robotic training to begin outside the operating theatre with the aid of simulation. Currently, surgeons attend short training courses to learn basic robotic skills using cadaveric and live animal models [35]. However, it is beyond the scope of these courses to teach an inexperienced robotic surgeon the necessary skills to perform a specific procedure [36]. At present these higher skills are either self-taught or learnt via proctoring, though this is difficult due to the shortage of competent practitioners.

In the future it may be possible to acquire the skills necessary for robotic surgery by using computer-based simulators. The technology can be readily applied to robotics with the master console of the robot acting as the user interface of the simulator [37]. Other centres are developing augmented reality systems for robotics, which enable anatomy to be overlaid on the image seen by the surgeon [38]. This technology, if applied to colorectal surgery, could perhaps be used to mark the position of the sacral nerves thereby reducing the incidence of iatrogenic injury.

The present telemanipulators, despite their sophistication, only represent the first generation of this technology and further advances are likely to occur rapidly. Currently, there is a lack of tools designed specifically for colorectal surgery but the introduction of bowel graspers, cautery scissors and a fourth robotic (da Vin$\mathrm{ci}^{\mathrm{TM}}$ ) arm may facilitate robotic colorectal surgery in the future. The integration of tactile feedback and smaller robots would greatly assist in the field of colorectal surgery, with the latter facilitating patient and robot repositioning.

\section{Conclusion}

The minimally invasive approach has revolutionised surgical care over the past 20 years though the growth of colorectal laparoscopic surgery remains relatively slow. One reason for this remains the technical difficulty of performing complex surgery with conventional laparoscopic instruments. Telemanipulators provide the surgeon with an unprecedented tool to perform minimally invasive surgery. The studies discussed demonstrate the feasibility and safety of performing complex colorectal surgery with robotic assistance. Although many of these studies have shown comparable results when compared to conventional laparoscopic procedures, none have yet demonstrated a clear advantage to using telemanipulators in colorectal surgery. They have highlighted some limitations of applying this technology to the field of colorectal surgery including the lack of tactile feedback and the difficulty in manoeuvring these cumbersome systems during the procedure.

In an analogous manner to laparoscopic surgery, it will take time to establish the operations, which will truly benefit from this robotic technology. The high initial cost of robotics will only be offset if these systems allow more surgeons to perform procedures in a minimally invasive manner thus providing real patient benefits. Only through larger trials will these benefits be demonstrated enabling further expansion of this exciting technology. 


\section{References}

1 Soper NJ, Barteau JA, Clayman RV, Ashley SW, Dunnegan DL: Comparison of early postoperative results for laparoscopic versus standard open cholecystectomy. Surg Gynecol Obstet 1992;174:114-118.

2 Vander Velpen GC, Shimi SM, Cuschieri A: Outcome after cholecystectomy for symptomatic gallstone disease and effect of surgical access: Laparoscopic vs. open approach. Gut 1993;34:1448-1451.

3 Darzi A, Lewis C, Menzies-Gow N, Guillou PJ, Monson JR: Laparoscopic abdominoperineal excision of the rectum. Surg Endosc 1995;9: 414-417.

4 Hasegawa H, Kabeshima Y, Watanabe M, Yamamoto S, Kitajima M: Randomized controlled trial of laparoscopic versus open colectomy for advanced colorectal cancer. Surg Endosc 2003; 17:636-640.

5 Phillips EH, Franklin M, Carroll BJ, Fallas MJ, Ramos R, Rosenthal D: Laparoscopic colectomy. Ann Surg 1992;216:703-707.

6 Jacobs M, Verdeja JC, Goldstein HS: Minimally invasive colon resection (laparoscopic colectomy). Surg Laparosc Endosc 1991; 1: 144-150.

7 Lo P, Ahmed N, Chung RS: Which laparoscopic operations are the fastest growing in residency programs? (abstract) Surg Endosc 2001; 15(suppl 1):145.

8 Dion YM, Gaillard F: Visual integration of data and basic motor skills under laparoscopy. Influence of 2-D and 3-D video-camera systems. Surg Endosc 1997;11:995-1000.

9 Ballantyne GH: The pitfalls of laparoscopic surgery: Challenges for robotics and telerobotic surgery. Surg Laparosc Endosc Percutan Tech 2002;12:1-5.

10 Schurr MO, Breitwieser H, Melzer A, Kunert W, Schmitt M, Voges U, et al: Experimental telemanipulation in endoscopic surgery. Surg Laparosc Endosc 1996;6:167-175.

11 Ahmed S, Hanna GB, Cuschieri A: Optimal angle between instrument shaft and handle for laparoscopic bowel suturing. Arch Surg 2004; 139:89-92.

12 Bennett CL, Stryker SJ, Ferreira MR, Adams J, Beart RW Jr: The learning curve for laparoscopic colorectal surgery. Preliminary results from a prospective analysis of 1,194 laparoscopic-assisted colectomies. Arch Surg 1997; 132:41-44.

13 Wishner JD, Baker JW Jr, Hoffman GC, Hubbard GW, Gould RJ, Wohlgemuth SD, et al: Laparoscopic-assisted colectomy. The learning curve. Surg Endosc 1995;9:1179-1183.
14 Nduka CC, Monson JR, Menzies-Gow N, Darzi A: Abdominal wall metastases following laparoscopy. Br J Surg 1994;81:648-652.

15 COLOR: A randomized clinical trial comparing laparoscopic and open resection for colon cancer. Dig Surg 2000;17:617-622.

16 Nelson H, Weeks JC, Wieand HS: Proposed phase III trial comparing laparoscopic-assisted colectomy versus open colectomy for colon cancer. J Natl Cancer Inst Monogr 1995; 19: 51-56.

17 Tang CL, Eu KW, Tai BC, Soh JG, MacHin D, Seow-Choen F: Randomized clinical trial of the effect of open versus laparoscopically assisted colectomy on systemic immunity in patients with colorectal cancer. Br J Surg 2001; 88:801-807.

18 Patankar SK, Larach SW, Ferrara A, Williamson PR, Gallagher JT, DeJesus S, et al: Prospective comparison of laparoscopic vs. open resections for colorectal adenocarcinoma over a ten-year period. Dis Colon Rectum 2003; 46: 601-611.

19 Watanabe M, Hasegawa H, Yamamoto S, Baba H, Kitajima M: Laparoscopic surgery for stage I colorectal cancer. Surg Endosc 2003; 17 : 1274-1277.

20 Zmora O, Gervaz P, Wexner SD: Trocar site recurrence in laparoscopic surgery for colorectal cancer. Surg Endosc 2001;15:788-793.

21 Allaf ME, Jackman SV, Schulam PG, Cadeddu JA, Lee BR, Moore RG, et al: Laparoscopic visual field. Voice vs. foot pedal interfaces for control of the AESOP robot. Surg Endosc 1998; 12:1415-1418.

22 Aiono S, Gilbert JM, Soin B, Finlay PA, Gordan A: Controlled trial of the introduction of a robotic camera assistant (EndoAssist) for laparoscopic cholecystectomy. Surg Endosc 2002; 16:1267-1270.

23 Merola S, Weber P, Wasielewski A, Ballantyne $\mathrm{GH}$ : Comparison of laparoscopic colectomy with and without the aid of a robotic camera holder. Surg Laparosc Endosc Percutan Tech 2002;12:46-51.

24 Hildebrandt U, Plusczyk T, Kessler K, Menger MD: Single-surgeon surgery in laparoscopic colonic resection. Dis Colon Rectum 2003;46: 1640-1645.
25 Cadiere GB, Himpens J, Vertruyen M, Bruyns J, Fourtanier G: Nissen fundoplication done by remotely controlled robotic technique (in French). Ann Chir 1999;53:137-141.

26 Cadiere GB, Himpens J, Germay O, Izizaw R, Degueldre M, Vandromme J, et al: Feasibility of robotic laparoscopic surgery: 146 cases. World J Surg 2001;25:1467-1477.

27 Delaney CP, Lynch AC, Senagore AJ, Fazio VW: Comparison of robotically performed and traditional laparoscopic colorectal surgery. Dis Colon Rectum 2003;46:1633-1639.

28 Giulianotti PC, Coratti A, Angelini M, Sbrana $\mathrm{F}$, Cecconi S, Balestracci $\mathrm{T}$, et al: Robotics in general surgery: Personal experience in a large community hospital. Arch Surg 2003;138: 777-784

29 Talamini MA, Chapman S, Horgan S, Melvin WS: A prospective analysis of 211 robotic-assisted surgical procedures. Surg Endosc 2003; 17:1521-1524.

30 Vibert E, Denet C, Gayet B: Major digestive surgery using a remote-controlled robot: The next revolution. Arch Surg 2003;138:10021006.

31 Weber PA, Merola S, Wasielewski A, Ballantyne GH: Telerobotic-assisted laparoscopic right and sigmoid colectomies for benign disease. Dis Colon Rectum 2002;45:1689-1694.

32 Rockall TA, Darzi A: Robot-assisted laparoscopic colorectal surgery. Surg Clin North Am 2003;83:1463-1468, xi.

33 Munz Y, Moorthy K, Kudchadkar R, Hernandez JD, Martin S, Darzi A, et al: Robotic assisted rectopexy. Am J Surg 2004; 187:88-92.

34 Prasad SM, Maniar HS, Soper NJ, Damiano RJ Jr, Klingensmith ME: The effect of robotic assistance on learning curves for basic laparoscopic skills. Am J Surg 2002; 183:702-707.

35 Chitwood WR Jr, Nifong LW, Chapman WH, Felger JE, Bailey BM, Ballint T, et al: Robotic surgical training in an academic institution. Ann Surg 2001;234:475-484.

36 Ballantyne GH, Kelley WE Jr: Granting clinical privileges for telerobotic surgery. Surg Laparosc Endosc Percutan Tech 2002; 12:17-25.

37 Rotnes JS, Kaasa J, Westgaard G, Eriksen EM, Hvidsten PO, Strom K, et al: Digital trainer developed for robotic assisted cardiac surgery. Stud Health Technol Inform 2001;81:424430.

38 Coste-Maniere E, Adhami L, Mourgues F, Carpentier A: Planning, simulation, and augmented reality for robotic cardiac procedures: The STARS system of the ChIR team. Semin Thorac Cardiovasc Surg 2003;15:141-156. 